\title{
Company internationalizing Issues within the FSSCs Examined in China
}

\author{
Pengwu Wang ${ }^{1, \text { a }}$, Xun Zhao ${ }^{2, b}$ \\ ${ }^{1}$ School of Accounting, Harbin University of Commerce, Harbin, 150028, China \\ ${ }^{2}$ School of Accounting, Harbin University of Commerce, Harbin, 150028, China \\ aemail:wangpengwu2003@126.com \\ bemail:ligeiafancyyou@gmail.com
}

Keywords: Internationalization, China, advanced financial shared service centre, continuous improvement, expansion and sustainability

\begin{abstract}
This study assesses the complex issues remained with China's rapid business growth and the emergence of mega multi-national enterprises by studying the current situation in our country and abroad for measure the progresses. The assessment focuses on a financial operating model called FSSCs, and analyzes the application derived from information of China Vanke to see if there exists room for improvement. However, the information in China contains so few studies on how to develop advanced FSSCs that it fails to cope with industry change. Case analysis revealed the benefits and limitations within the FSSCs examined. The findings have clearly emphasized the needs to create FSSCs with Chinese characteristics, which might be a more appropriate method for Chinese finance in the future.
\end{abstract}

\section{Introduction}

Apparently for Chinese companies, there are many projects and businesses they have to deal with. So how to manage the projects and businesses effectively becomes a new challenge for Chinese companies. In this situation, a specific financial model called FSSCs comes into being. But most concrete structures in finance operating model are inevitably subjected to accounting shared services including some simple interactive processes. There exist three reasons for conducting this research. Firstly, economics is converging because of the pressures of competition in the world. Secondly, globalization makes the multi-national companies optimize costs without weakening the operating and economic efficiency. Thirdly, connection and interaction among multi-national corporations in the world become more frequent, which are related to processes, technology, human resources, service and information, etc.Therefore, this paper is going to address the context in contemporary China and then to analysis the detailed application issues of FSSCs under internationalization. The understanding gained will help finance service centres' expansion and sustainability. This can be a core engine for analytical capability. In particular what the barriers are how to develop and build global finance operating model and whether China FSSCs lack mindset of continuous improvement, which will be considered and discussed as key issues.

\section{Current application of FSSCs under internationalization}

Buckley and Ghauri(1999) defined internationalization as "the growing tendency of corporations to operate across national boundaries". There are lots of enterprises want to become international for the reason of traditional motivations and emerging motivations. The traditional motivations are to guarantee essential supplies. As to emerging motivations, they can serve economic, technological and social development. It is the high time that finance shared service centre should be further applied to deliver more value that go beyond finance.

SSC emerged in the early 1990s as large decentralized companies involved several functional areas with its own missions, typically some simple interactive processes, and degrees of responsibility. However, those essential functions are not enough for current business environment. 
FSSCs have undergone several rapid evolutionary cycles. Intro-corporate activities and financial transformations accelerated the rise of Finance Shared Services 2.0 by KPMG report. With the globalization of economy, business advancement and continuous improvement, the listed firms have sought to develop multi-functional capability and to enhance decision support capability to develop high-value programs for innovation that leverage FSS redesigning powers. FSSCs also improved financial transformation program such as the adoption of a global ERP systems. Up to 500 FTE's is most common. Over $60 \%$ of Fortune 500 companies now have shared service structures. Motivation for this can be a benefit of cost reduction and enhance strategic objectivity of companies.

The impressive FSSCs' development in China reflects Chinese business development. Most of the participating FSSCs were established between 2010 and 2012. In the past decades, FSS mainly gained from activity splits and standardizing the process. Aiming at improving customer satisfaction, service quality, companies that seek to bring about more value from shared services need to enable the extending across functional areas to join in more advanced analytical activities.

\section{Case Study of Financial Sharing Application of China Vanke Co., Ltd.}

CHINA VANKE CO.,LTD is a China-based company engaged in real estate development and proper management businesses. The Company mainly develops commercial residential houses, as well as provides property management services. Monthly sales now surpass RMB 428.8 billions and continue to seek opportunities in new ventures around the world. With the expansion of the Group, home and abroad, it has begun to innovate the traditional business. In order to ensure its leading edge in the industry and to further enhance resource management and risk management, the FSSC had been created for pursuing speed, scale, quality and efficiency. In 2013, Vanke examined its financial strategy and found that the dynamics of the major domestic appliance business in China had changed dramatically. At present, the first-phase financial sharing project of all real estate companies and one-third of property companies in the group has been successfully launched. The status quo and problems of financial sharing centers is mainly analyzed from the following respects:

\subsection{Management mode.}

FSSC can be expanded horizontally or vertically. The financial sharing service model is not initiated by the finance department, but is generated by the management changes of enterprises. As companies grow in size, business types and management levels continue to increase, The financial sharing center currently belongs to multi-system integration, traditional financial management model has become a bottleneck restricting the development of enterprises. At this time, enterprises must stand at the strategic level, carry out their own management changes, and seek breakthroughs in the transformation. There are some problems in the traditional phase: lack of application, ease of use, response speed, and actual business integration.

\subsection{Financial organization.}

In the shared service model, deep changes in the financial organizational structure must be made. After the management changes, the financial department is required to provide information in an efficient and multi-dimensional way to meet the needs of enterprise management and development, and the traditional decentralized or centralized financial structure cannot fully meet these needs, and many processes are difficult to standardize. For the user's problems, a professional support service team handles the issues and meet their needs, but the professional capabilities need to be strengthened.

\subsection{The high cost of ERP resources.}

The financial information system of an enterprise is the basis and guarantee for the realization of financial sharing services, so an unified ERP system is a key factor in ensuring the smooth construction of a shared service platform. In order to meet the needs of the financial sharing center, it is necessary to assign a person to design the information management mode of the financial 
sharing center and improve the information system management function. These costs are enormous, even causing a serious burden on the enterprise. This also need to ensure the complete understanding of the unique requirement setting and have experience of the implementation of the FSSCs.

\subsection{Diminishing returns.}

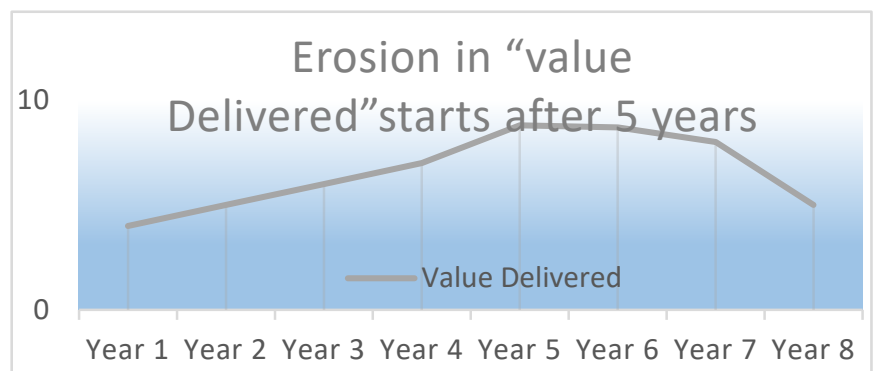

The line chart below presents the status quo of value delivered in China Vanke, representing the trends of diminishing returns. A majority of companies are satisfied with the status quo. While forward-thinking financial practices, others may think there is no need to further reorganization and investment is needed. But as new technologies, business processes and market opportunities emerge, companies remain stand still and risk of losing competitive advantage. As the line chart shows, SSC needs to be part of a long-term strategy rather than a short-term cost-cutting tactic.

\section{Finalize strategy and develop continuous improvement for FSSC journey}

According to Deloitte reports, There are 60\% enterprises resist to change, $44 \%$ have limitations of existing systems, 30\% lack of cross-functional team and 20\% technology staff and users not involved. In order to cope with the challenges mentioned above in China, it is critical that finance model should be align with corporate strategy. For change to be successfully, people in the organization should hear about what is going on. That is a communication strategy. Communications manufacturer attains low cost and high value. According to SSNO-2015 Annual State of Shared Services Report, shared services CI team tops the list of challenges. Therefore, they should build in the expectation that the operating model will evolve for the better over time, and reshape the finance function to drive particular capacities from its finance shared service operations. That is continuous improvement mindset. Also, in order to meet the corporate strategy, the maturity model can help to conform a end-state vision across all the crucial aspects. Considerations of culture, business model, skill sets and customer expections and other factors that make the company choose the best form for focusing on high value business and intelligence programs.

\section{Findings and discussion}

With administration of global finance operating model, the move to FSSC maturity is a never-ending commitment to projects to improve efficiency and effectiveness of the finance organization. Our results indicate that the next generation FSSC should not stand alone but rather multiple points of presence that can serve global clients. KPMG institutes also reports the advanced FSSC is an evolutionary journey of expansion and sustainability. The findings from PWC report (Shared Services: Multiplying Success) seem consistent with our study, which further identified standardization and automation as upcoming challenges to remain competitive. The proposed findings have given a novel route for the evolution of finance operating model and can be used for different organizations.

\section{Conclusion}

Based on the literature, the research has drawn out three conclusions:

1) Internationalization has a positive effect on FSSCs implementation. This can be used because 
it is in the internationalizing environment.

2) China FSSCs should inclined to develop maturity model in practice. And this vision can also be called continuous improvement.

3) There is a lack of sustainability in China FSSCs. The maturity model can be sustrumental in understanding where your FSSC is winning. It provides solutions that drives top line revenue while expanding geographic reach and keeping sustainability.

As the discussion shows above, under the influence of Chinese traditional business model and objective social factors, FSSCs with Chinese characteristics might be a more appropriate method for China finance in the future.

As mentioned, there are several barriers to implement FSSC that should be further considered in the feasibility study in the subsequent phase. All beneficial levels such as multi-functionality and automation will force companies to rethink their service delivery strategy and to develop new business models in order to realize advanced efficiency and improve effectiveness of services.

\section{Acknowledgements}

The arthors wish to acknowledge the support of 2017 Heilongjiang Province Philosophy and Social Science Research Planning Project Supporting Co-construction Project "Strategic Map Thinking-oriented Heilongjiang Province Deepening the Reform Path of State-owned Enterprises" (17JLE332); 2017 Harbin Commercial University-level scientific research project general project "Institutional Innovation Drive, Financial Governance and Promotion of Heilongjiang Province State-owned Enterprise Development Vitality Research" (17XN078); 2018 Provincial Accounting Society Accounting Research Project "New Period Heilongjiang Research on Path Selection of High-Quality Development of CPA Industry to Revitalize Longjiang Economy" (2018035).

\section{References}

[1] Zhong Bang xiu. Innovation of financial management of group companies based on shared service concept [J]. business accounting. 2012 (19): 15-16

[2] Li Wen 1, Xu Qingdong, Chen Xinqiao. Evaluation of the Financial Shared Services of state owned, transnational and private enterprises, [J]. financial journal Monthly. 2018 (3): 115-125.

[3] Ge Jing, Hao Jia Jia. Performance evaluation of corporate finance sharing center in the era of big data [J]. business accounting 2018 (2): 125-126.

[4] Qi Qiong. Implementation and evaluation of Multinational Financial Shared Service Center mode [J]. accounting communications 2015 (32): 38-40.

[5] Information on http://www.reuters.com. 